\title{
SYNTHESIS OF INDIUM TIN OXIDE NANOPARTICLES BY A NONHYDROLYTIC SOL-GEL METHOD
}

\author{
Gabriel M. Silva ${ }^{\dagger}$ Emerson H. de Faria, Eduardo J. Nassar*, Katia J. Ciuffi e Paulo S. Calefi
}

Universidade de Franca, Av. Dr. Armando Salles Oliveira, 201, 14404-600, Franca - SP, Brasil

Recebido em 31/3/11; aceito em 20/9/11; publicado na web em 6/12/11

\begin{abstract}
Indium tin oxide nanoparticles were synthesized in two different sizes by a nonhydrolytic sol-gel method. These powders were then transformed into ITO via an intermediate metastable state at between 300 and $600{ }^{\circ} \mathrm{C}$. The presence of characteristic O-In-O and $\mathrm{O}-\mathrm{Sn}-\mathrm{O}$ bands at 480 and $670 \mathrm{~cm}^{-1}$ confirmed the formation of ITO. The X-ray diffraction patterns indicated the preferential formation of metastable hexagonal phase ITO (corundum type) as opposed to cubic phase ITO when the reflux time was less than $3 \mathrm{~h}$ and the heat treatment temperature was below $600{ }^{\circ} \mathrm{C}$. Particle morphology and crystal size were examined by scanning electron microscopy.
\end{abstract}

Keywords: ITO; sol-gel nonhydrolitic; nanoparticles.

\section{INTRODUCTION}

ITO is a mixed indium and tin oxide whose composition may vary depending on its application, but which typically consists of 80 to $90 \%$ indium oxide with the remainder corresponding to tin IV oxide. This material shows very good conductivity and transmission performance allied to excellent stability, reproducibility and morphology. It has optical and electronic applications in devices such as solar cells, gas sensors, organic electroluminescent devices, functional glasses, thermal mirrors and solid electrolyte cells. In thin film form, it possesses high electrical conductivity and transparency in the visible region, combined with low electrical resistance. ${ }^{1-3}$

ITO particles have been obtained by various techniques, such as thermal hydrolysis, thermal decomposition, spray pyrolysis, and coprecipitation. ${ }^{4-7}$ However, these methods have not proved very successful in obtaining nanometric particles due to the high degree of agglomeration presented by the oxide. Other methods that have been used include direct precipitation, co-precipitation, and hydrothermal methods, but these do not allow for control of the particle size distribution.

New techniques for obtaining metal oxides with controlled morphological characteristics have recently been developed. Among these techniques, the sol-gel method stands out for its advantages, such as the possibility of obtaining high purity materials using simple equipment. ${ }^{7-12}$ Another advantage of the sol-gel method is the ability to process the material in the form of thin films, which, in the particular case of ITO, is the only technique that allows for deposition on relatively large substrates at a feasible cost. ${ }^{13,14}$

The sol-gel methodology comprises wet and dry routes. One of the dry routes is the sol-gel method for nonhydrolytic gels (NHG), developed in the 1990s as an alternative to the hydrolytic sol-gel route. ${ }^{7-10}$ One of the advantages of the NHG method is the greater homogeneity achieved for heterometallic oxides, not easily achieved by the hydrolytic sol-gel route due to the different reactivities of their alkoxides. ${ }^{9-12}$ Promising results have been obtained through the NGH method, which not only allows for greater reproducibility but also involves the use of less expensive precursors, thus representing lower costs and better quality. ${ }^{9-11,15,16}$

The nonhydrolytic sol-gel process used in this work is an adaptation of the NGH method used by other research groups. ${ }^{7,8,10,12,15}$ The

*e-mail: ejnassar@unifran.br

In Memoriam process is run in an open system, with an inert atmosphere produced by means of constant bubbling of argon, using the oxygen donor itself as a solvent. ${ }^{9,11,15,16}$

This work studied the synthesis of ITO in xerogel form, using the nonhydrolytic sol-gel process. The parameters studied were influence of reflux time and heat treatment temperature. The samples obtained were characterized by thermogravimetric analyses (TG/DTG and DTA), infrared absorption spectroscopy (FTIR), X-ray diffraction (XRD), and scanning electron microscopy (SEM).

\section{EXPERIMENTAL}

The ITO was prepared by keeping $27 \mathrm{mmol}$ of $\mathrm{InCl}_{3}$ and $3 \mathrm{mmol}$ of $\mathrm{SnCl}_{4}$ in $100 \mathrm{~mL}$ of ethanol anhydrous under reflux for $5 \mathrm{~h}$ in an argon atmosphere, similarly to the procedure employed in other studies conducteds by our group..$^{9,10}$ To study the effect of reflux time, aliquots of the material were removed at $1 \mathrm{~h}$ intervals. The xerogel was obtained by evaporation of the solvent and presented the greenish hue typical of InOOH and $\mathrm{In}(\mathrm{OH})_{3} .{ }^{1}$ To study the temperature of ITO formation, after determining the mass loss temperatures based on the TG and DTG curves, the xerogel obtained after $4 \mathrm{~h}$ of reflux was heat-treated for $2 \mathrm{~h}$ at $300,530,600$ and $850{ }^{\circ} \mathrm{C}$. For the study of the reflux time, the materials were kept at $600{ }^{\circ} \mathrm{C}$ for $2 \mathrm{~h}$. The resultant materials were then characterized by XRD, FTIR and SEM.

The thermal analyses (TG/DTG and DTA) were carried out with an SDT Q600 -imultaneous DTA-TG analyzer (TA Instruments), applying a heating rate of $20^{\circ} \mathrm{C} / \mathrm{min}$. The X-ray diffractograms were obtained on a Rigaku Miniflex diffractometer with $\mathrm{Cu} \mathrm{K} \alpha$ $\left(\lambda=1.54 \AA\right.$ ) monochromatic radiation, at a scan step of $0.02^{\circ}$. The infrared absorption spectra were measured in a Bomem MB 100 spectrophotometer with Fourier transform using $\mathrm{KBr}$ pellets. The SEM micrographs were obtained in the structural characterization laboratory of DEMa-UFSCar, using a Philips XL 30 FEG scanning electron microscope.

\section{RESULTS AND DISCUSSION}

The thermal analyses (TG/DTG and DTA) of the xerogel obtained after $4 \mathrm{~h}$ of reflux (Figure 1) revealed five endothermic stages of mass loss. The first two stages, which occurred between 35 and $250{ }^{\circ} \mathrm{C}$, were attributed to elimination of the solvent and the oxygen donor (ethanol) used in the synthesis, and to dehydration of the $\mathrm{InOOH} \mathrm{n}_{2} \mathrm{O}$ precursor. The proceeding two stages, from 480 to $570{ }^{\circ} \mathrm{C}$, corresponded to 
dehydroxylation and conversion of the hydroxides into oxides. The last stage, centered at $800^{\circ} \mathrm{C}$, can be attributed to particle growth or phase change, as reported by Li et al. ${ }^{17}$ The percentage of mass loss between 35 and $250{ }^{\circ} \mathrm{C}$ representeds $40.02 \%$, and that above $480{ }^{\circ} \mathrm{C}$ correspondeds to $54.64 \%$. In the initial system, the precursors $\mathrm{InCl}_{3}$ and $\mathrm{SnCl}_{2}$ comprise $7.97 \%$ of the weight, whereas ethanol compriseds $92.02 \%$ of the weight. Therefore, one mol of chloride produced $1 / 2 \mathrm{~mol}$ of oxide, namely the $\operatorname{In}_{2} \mathrm{O}_{3}$ :Sn final product, and theoretically the final residue would be ITO, accounting for $4.15 \%$ of the initial weight. The experimental TG curve evidenceds a final residue corresponding to 5.35 and $94.65 \%$ of total weight loss, which was in agreement with the theoretical value. The powder yielded by the heat treatment at $850{ }^{\circ} \mathrm{C}$ was yellowish, typical of the cubic phase of ITO. ${ }^{1,18}$
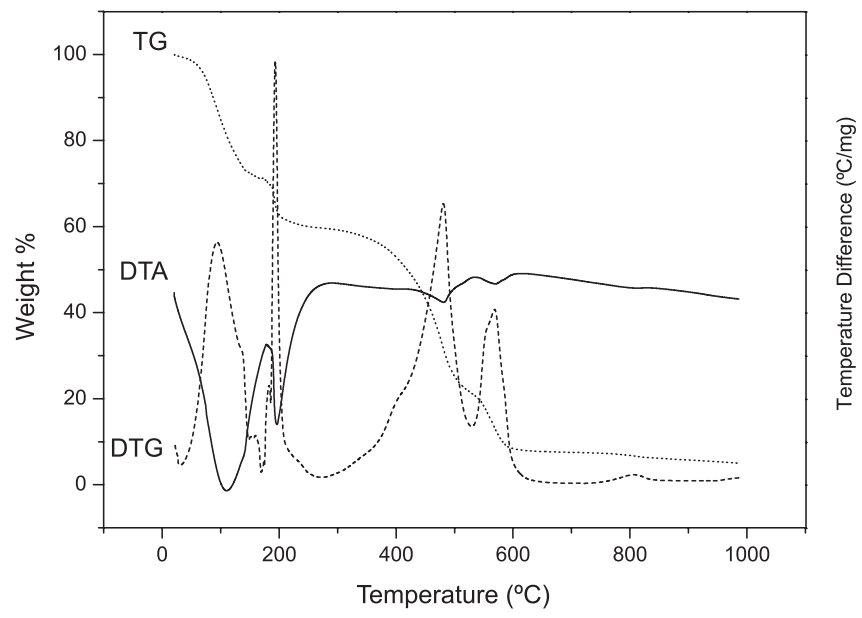

Figure 1. Thermogravimetric analysis of the xerogel in a nitrogen atmosphere

The DTG curve can provide the speed of the decomposition as a function of the decomposed fraction. The first and second stages have decomposition speeds ( 0.49 and 0.40 , respectively) that are lower than those of the third and four stages (0.72). This lower speed value can be ascribed to the large amount of solvent that is evaporated, as discussed for the DTA curve.

The DTA curve displays broad endothermic peaks. There is a reduction in the area under these peaks, which is consistent with the amount of decomposed material. The first peak has the largest area and can be ascribed to solvent evaporation. The decrease in the area of other peaks may be due to decomposition of the residual organic molecules and dehydroxylation accompanied by loss of water.

Figure 2 shows the infrared absorption spectra of the samples used to examine the effect of the heat treatment. The bands at 1615 and $3435 / 3450 \mathrm{~cm}^{-1}$ indicated the presence of water and/or ethanol adsorbed. The bands at 486, 875 and $1405 \mathrm{~cm}^{-1}$, which were attributed to $\mathrm{HO}-\mathrm{In}=\mathrm{O}, \mathrm{In}-\mathrm{OH}$ and $\mathrm{Sn}-\mathrm{OH}$, respectively, disappeared when the samples were treated at temperatures above $300^{\circ} \mathrm{C}$. The intensity of the band at $1100 \mathrm{~cm}^{-1}$, which appeared in the spectrum of the sample treated at $530{ }^{\circ} \mathrm{C}$ and diminished in the spectra of samples treated at higher temperatures, was attributed to the $\mathrm{In}-\mathrm{OH}$ surface groups. The spectra of the samples treated at 530,600 and $850{ }^{\circ} \mathrm{C}$ showed the characteristic bands of crystalline $\mathrm{In}_{2} \mathrm{O}_{3}$. The appearance of bands in the regions of 1510 to 1750 and 3740 to $3860 \mathrm{~cm}^{-1}$ in the spectra of samples treated at 530 and $600^{\circ} \mathrm{C}$, and disappearance for sample treated at $850^{\circ} \mathrm{C}$, indicated the formation of intermediate material. Taken together this evidence leads us to propose that the transformation of oxihydroxide into oxide begins at temperatures below $300{ }^{\circ} \mathrm{C} . .^{1,3,19-21}$ Table 1 depicts the attributions of the bands observed in the spectra.

The materials heat-treated at 530,600 and $850^{\circ} \mathrm{C}$ were characterized by X-ray diffraction (Figure 3 ).
Table 1. Assignment of the FTIR bands of the samples employed in the study of the effect of heat treatment $t^{1,3,18,22}$

\begin{tabular}{|c|c|c|c|c|c|}
\hline \multirow[t]{2}{*}{ Assignment } & \multicolumn{5}{|c|}{ band $\left(\mathrm{cm}^{-1}\right)$} \\
\hline & xerogel & $300^{\circ} \mathrm{C}$ & $530^{\circ} \mathrm{C}$ & $600^{\circ} \mathrm{C}$ & $850^{\circ} \mathrm{C}$ \\
\hline $\mathrm{HO}-\mathrm{In}=\mathrm{O}$ & 486 & 483 & & & \\
\hline \multirow[t]{4}{*}{ ITO } & & & 449 & 456 & 477 \\
\hline & & & 540 & 540 & 540 \\
\hline & & & 564 & 566 & 570 \\
\hline & & & 603 & 600 & 609 \\
\hline $\mathrm{In}-\mathrm{OH}$ & 875 & 875 & & & \\
\hline $\mathrm{H}_{2} \mathrm{O}_{\text {(adsorbed) }}$ & 1615 & 1615 & & & \\
\hline $\mathrm{In}-\mathrm{OH}_{\text {(surface groups) }}$ & & & 1100 & 1100 & \\
\hline $\mathrm{Sn}-\mathrm{OH}$ & 1405 & & & & \\
\hline \multirow[t]{5}{*}{ In-OH } & & & 1512 & 1518 & \\
\hline & & & 1546 & 1546 & \\
\hline & & & 1648 & 1651 & \\
\hline & & 1699 & 1699 & 1693 & \\
\hline & & 1740 & 1740 & 1740 & \\
\hline $\mathrm{OH}_{\text {(alcohol and/or water) }}$ & 3450 & 3450 & & & 3435 \\
\hline \multirow[t]{3}{*}{$\mathrm{In}-\mathrm{OH}$ and/or $\mathrm{Sn}-\mathrm{OH}$} & & 3746 & 3746 & 3746 & \\
\hline & & 3833 & 3833 & 3833 & \\
\hline & & 3860 & 3860 & 3860 & \\
\hline
\end{tabular}

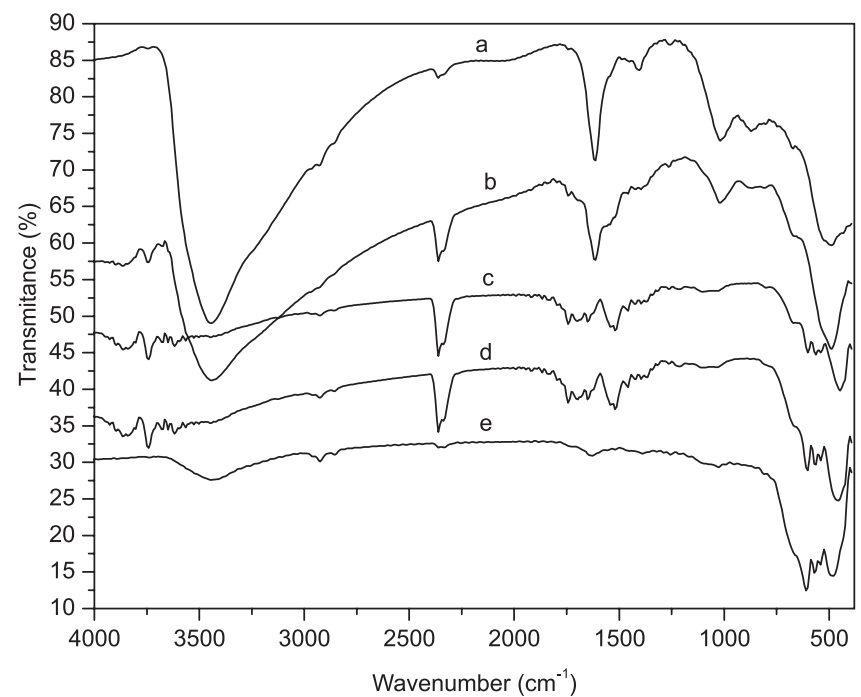

Figure 2. Infrared absorption spectra of samples treated at different temperatures: (a) without heat treatment, (b) at $300^{\circ} \mathrm{C},\left(\right.$ c) at $530^{\circ} \mathrm{C},\left(\right.$ d) at $600{ }^{\circ} \mathrm{C}$, and (e) at $850^{\circ} \mathrm{C}$

The samples treated at 600 and $850{ }^{\circ} \mathrm{C}$ presented $2 \theta$ lines characteristic of cubic phase ITO, ${ }^{17,19-22}$ with peaks of higher intensity relative to the 222,440 and 622 planes. In addition to these lines, the sample treated at $530^{\circ} \mathrm{C}$ exhibited peaks characteristic of metastable corundum phase $\mathrm{In}_{2} \mathrm{O}_{3}$ (JCPDS 22-336). Yu et al..$^{21}$ found that InOO1, crystallized or hydrated on the nanometric scale is a key factor for obtaining metastable $\mathrm{In}_{2} \mathrm{O}_{3}$ nanocrystals by thermal dehydration at temperatures above $490^{\circ} \mathrm{C}$. The fact that the infrared spectra of the samples without heat-treatment, as well those heat-treated at $300^{\circ} \mathrm{C}$ indicated the presence of In-OH allows us to infer that the xerogel obtained here contained a large quantity of In-OH groups and that their thermal conversion to 
cubic phase ITO involved the formation of hexagonal and metastable $\mathrm{In}_{2} \mathrm{O}_{3}$ at temperatures between 480 and $600{ }^{\circ} \mathrm{C}$. $^{21}$

The absence of lines characteristic of $\mathrm{InOOI}^{17}$ indicates the nonformation of this material. The presence of fine lines in the diffractogram indicates the high crystallinity of the materials.

Figure 4 shows the X-ray diffractograms of samples subjected to different reflux times.

The materials obtained from 1 and $2 \mathrm{~h}$ of reflux showed peaks characteristic of cubic and hexagonal (metastable) $\operatorname{In}_{2} \mathrm{O}_{3}$, while the materials obtained with longer reflux times showed only peaks related to the cubic phase. ${ }^{17,18,21,22}$

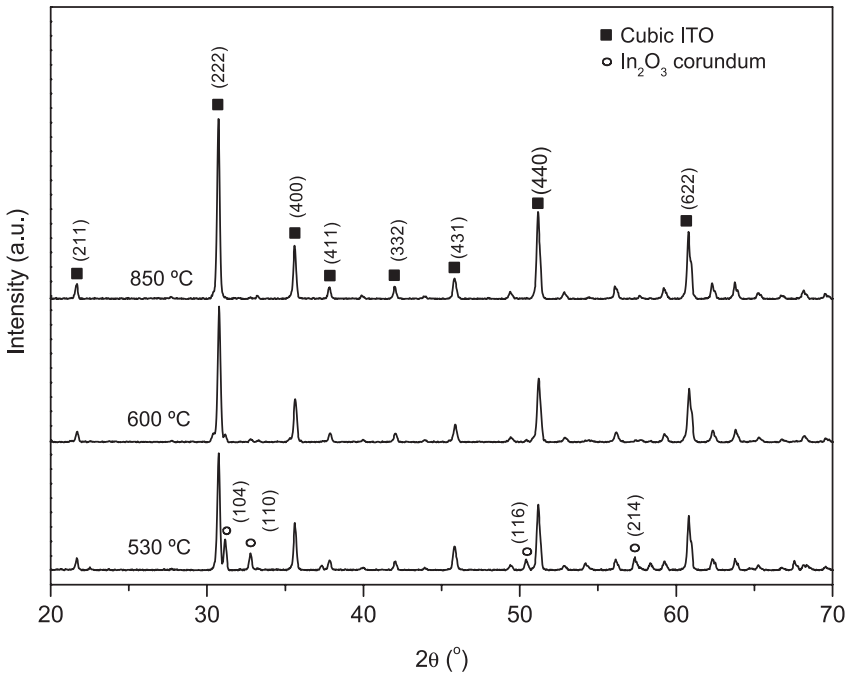

Figure 3. X-ray diffractograms of the samples treated at 530,600 and $850^{\circ} \mathrm{C}$
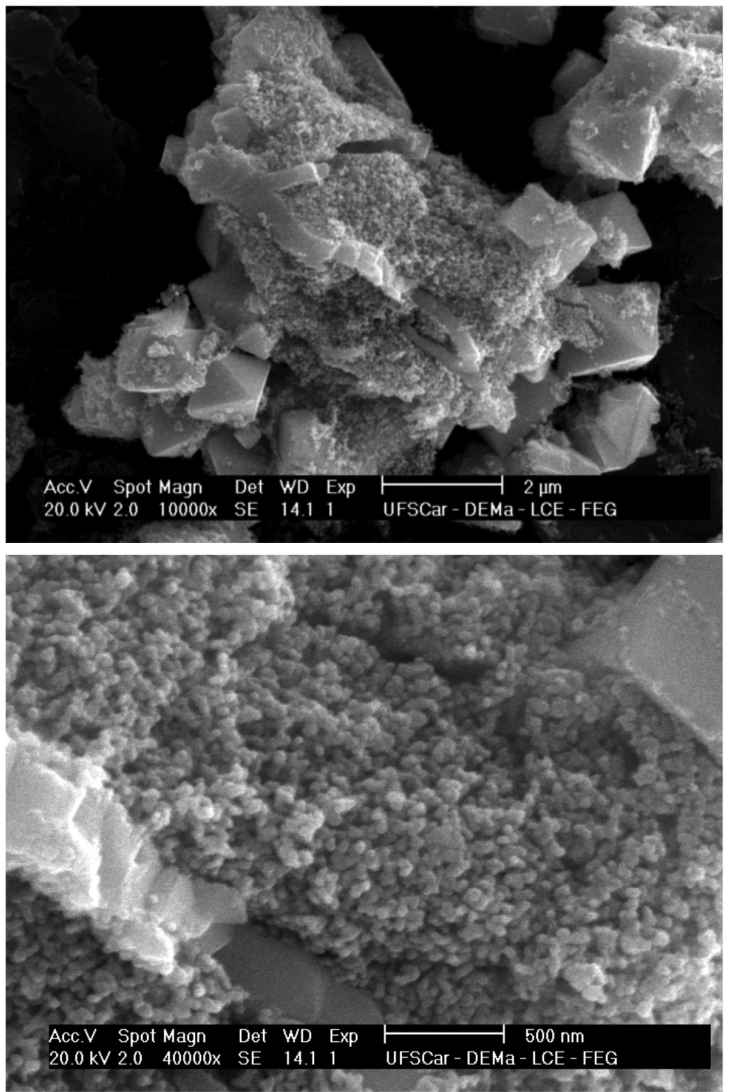

The results obtained in this study are consistent with those reported by Yu et al. ${ }^{21}$ who concluded that if the reaction time is short or the heat treatment temperature insufficient, the end product is a mixture of cubic and hexagonal $\operatorname{In}_{2} \mathrm{O}_{3}$.

Scanning electron microscopy was used to study the particle morphology of ITO. Figure 5 shows micrographs, in different magnitudes, of the sample treated at $600{ }^{\circ} \mathrm{C}$.

The micrographs reveal particle formation in two scale sizes, i.e., larger particles consisting of octahedra of approximately $1 \mu \mathrm{m}$. The octahedral particles are similar to the $\mathrm{In}_{2} \mathrm{O}_{3}$ particles obtained by Yang et al. ${ }^{17}$ after heating the aqueous solution of $\mathrm{InCl}_{3}$, while

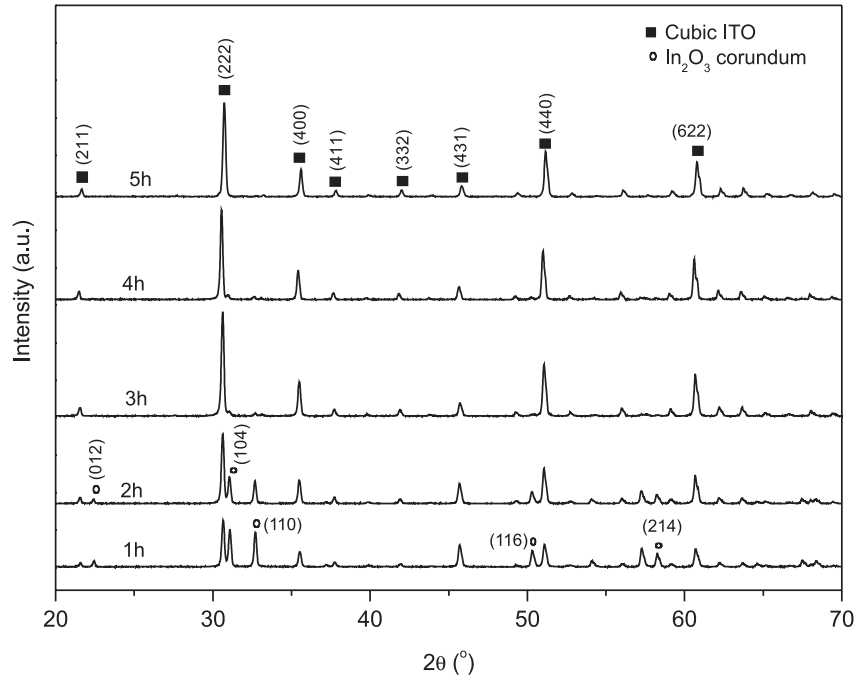

Figure 4. X-ray diffractograms of the samples with different reflux times, treated at $600{ }^{\circ} \mathrm{C}$
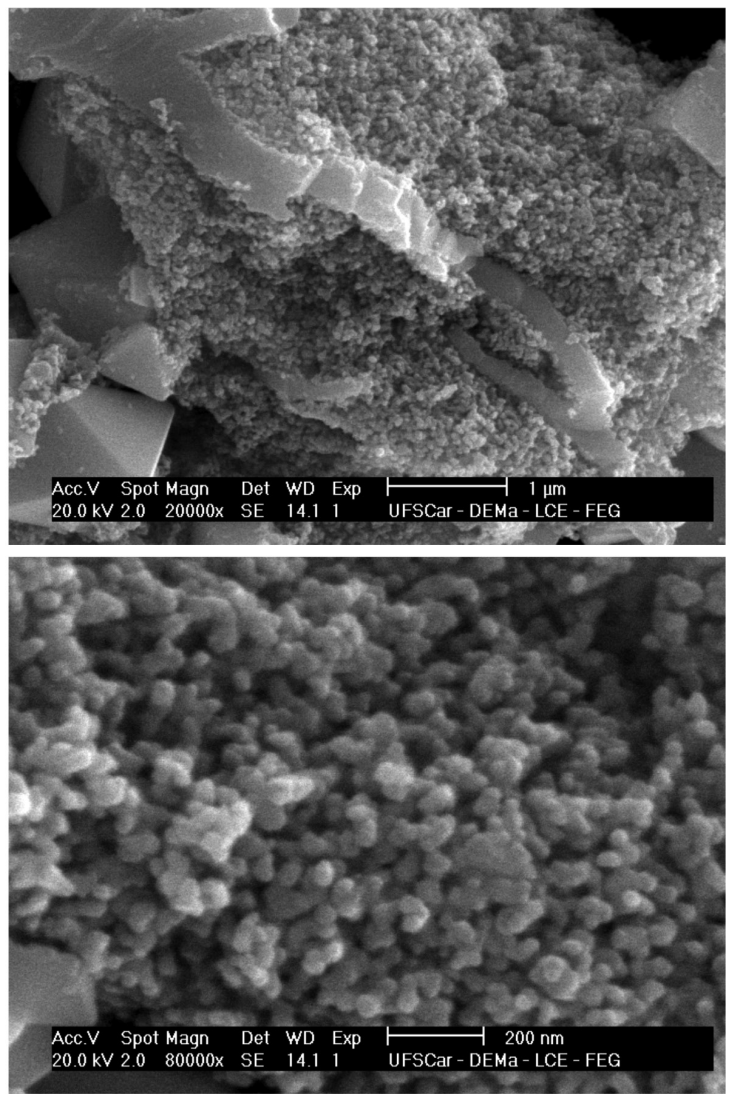

Figure 5. SEM micrographs, with different magnitudes, of the ITO xerogel obtained after $4 \mathrm{~h}$ of reflux and heat-treated at $600{ }^{\circ} \mathrm{C}$ 
the nanoparticles resemble those obtained by Han et al.,${ }^{23}$ who used a combination of the sol-gel and combustion methods. The cuboid-shaped nanoparticles were approximately $40 \mathrm{~nm}$ by SEM, but the ITO particles can be calculated using the Scherrer equation, on the basis of XRD results. The crystallite size of the crystal planes (222) and (440) was 43 and $46 \mathrm{~nm}$, respectively, consistent with SEM results.

Figure 6 depicts typical size distributions for the samples. The maximal distributions agree with the values obtained by the Scherrer equation.

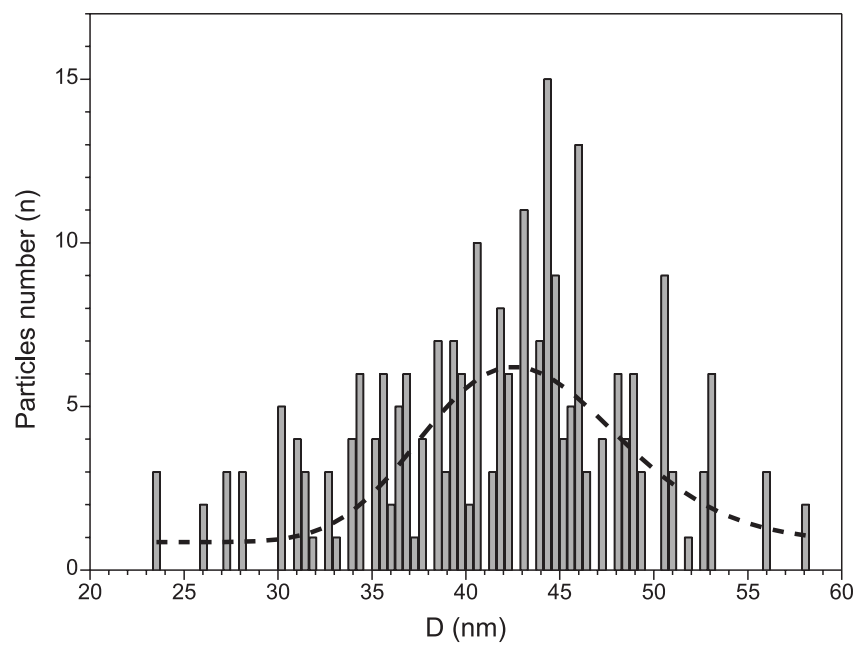

Figure 6. Typical size distributions for the ITO xerogel obtained after $4 \mathrm{~h}$ of reflux and heat-treated at $600{ }^{\circ} \mathrm{C}$. The line is just a guide to facilitate visualization of particle size distribution ( $n>235$ for the samples)

\section{CONCLUSION}

Indium tin oxide nanoparticles were prepared by the nonhydrolytic sol-gel method, resulting in a solid of high crystallinity and color characteristic of ITO. The results indicated that $3 \mathrm{~h}$ of reflux and heat treatment below $500{ }^{\circ} \mathrm{C}$ lead to the formation of the mixed oxide. This low temperature, allied with the low cost of the precursors (chlorides) and the fact that the synthesis without thermal treatment produces a colloidal suspension of precursor of ITO, opens up new prospects for the large-scale use of this method to produce films at lower costs than the traditional methods.

\section{ACKNOWLEDGMENTS}

The authors gratefully acknowledge the financial support of the
Brazilian research funding agencies Fundação de Amparo à Pesquisa do Estado de São Paulo (FAPESP), Conselho Nacinonal de Desenvolvimento Científico e Tecnológico (CNPq), and Coordenação de Aperfeiçoamento de Pessoal de Nível Superior (CAPES).

\section{REFERENCES}

1. Pramanik, N. C.; Das, S.; Biswas, P. K.; Mater. Lett. 2002, 26, 671.

2. Ba, J.; Rohlfing, D. F.; Feldhoff, A.; Brezesinski, T.; Djerdj, I.; Wark, M.; Niederberger, M.; Chem. Mater. 2006, 18, 2848.

3. Ho, W. H.; Yen, S. K.; Thin Solid Films. 2006, 498, 80.

4. Xu, H.; Yu, A.; Mater. Lett. 2007, 61, 4043.

5. Jang, H. D.; Seong, C. M.; Chang, H. K.; Kim, H. C.; Current Applied Physics 2006, 6, 1044.

6. Song, J. E.; Lee, D. K.; Kim, H. W.; Kim, Y. I.; Kang, Y. S.; Colloids Surf. A 2005, 257, 539.

7. Bouget, L.; Corriu, R. J. P.; Leclercq, D.; Mutin, P. H.; Vioux, A.; J. Non-Cryst. Solids 1998, 242, 81.

8. Mutin, P. H.; Vioux, A.; Chem. Mater. 2009, 21, 582.

9. de Lima, O. J.; Aguirre, D. P.; Oliveira, D. C.; Silva, M. A.; Mello, C.; Leite, C. A. P.; Sacco, H. C.; Ciuffi, K. J.; J. Mater. Chem. 2001, 11, 2476.

10. Vioux, A.; Chem. Mater. 1997, 9, 2292.

11. Caetano, B. L.; Rocha, L. A.; Molina, E.; Rocha, Z. N.; Ricci, G.; Calefi, P. S.; de Lima, O. J.; Mello, C.; Nassar, E. J.; Ciuffi, K. J.; Appl. Catal. A 2006, 311, 122.

12. Niederberger, M.; Acc. Chem. Res. 2007, 40, 793.

13. De, A.; Biswas, P. K.; Manara, J.; Mater. Charact. 2007, 58, 629.

14. Legnani, C.; Lima, S. A. M.; Oliveira, H. H. S.; Quirino, W. G.; Machado, R.; Santos, R. M.; Davolos, M. R.; Achete, C. A.; Cremona, M.; Thin Solid Films. 2007, 516, 193.

15. Acosta, S.; Corriu, R. J. P.; Leclercq, D.; Lefèvre, P.; Mutin, P. H.; Vioux, A.; J. Non-Cryst. Solids 1994, 170, 234.

16. Nassar, E. J.; Pereira, P. F. S.; Nassor, E. C. O.; Avila, L. R.; Ciuffi, K. J.; Calefi, P. S.; J. Mater. Sci. 2007, 42, 2244.

17. Yang, H.; Zhao, H.; Dong, H.; Yang, W.; Chen, D.; Mater. Res. Bull. 2009, 44, 1148

18. Lee, J-S.; Choi, S-C.; J. Eur. Ceram. Soc. 2005, 25, 3307.

19. Lin, S-E.; Wei, W-C. J.; J. Am. Ceram. Soc. 2008, 28, 1121.

20. Neri, G.; Bonavita, A.; Micali, G.; Rizzo, G.; Pinna, N.; Niederberger, M.; Ba, J.; Sens. Actuators, B 2008, 130, 222.

21. Yu, D.; Wang, D.; Qian, Y.; J. Solid State Chem. 2004, 177, 1230.

22. Li, S.; Qiao, X.; Chem, J.; Wang, H.; Jia, F.; Qiu, X.; J. Cryst. Growth 2006, 289, 151

23. Han, C.-H.; Han, S.-H.; Gwak, J.; Khatkar, S. P.; Mater. Lett. 2007, 61, 1701. 